\title{
Electroporation of Schizosaccharomyces pombe by hyperosmotic post-pulse incubation
}

\author{
Minoru Suga, Isamu Kusanagi, and Toyomasa Hatakeyama \\ Toyama University, Toyama, Japan
}

BioTechniques 36:218-220 (February 2004)

The fission yeast Schizosaccharomyces pombe is attractive for molecular biological investigation because of its resemblance to higher eukaryotic cells. These days, $S$. pombe is transformed largely through electroporation; to obtain high-transformation efficiency, foreign DNA is introduced into intact cells (1-3). For still greater efficiency, several attempts have been made to pretreat intact $S$. pombe cells before the electric pulse is applied. These attempts have included pretreatment with dithiothreitol (DTT) (4) or hyperosmotic solution (5) and freezing in sorbitol with calcium (6). However, when $S$. pombe cells are pulsed in a polyethylene glycol (PEG) solution and continuously postincubated, the pores of the plasma membrane are maintained, but the efficiency is impractically low (7). We found that a switch to hyperosmotic solution buffer for the post-pulse incubation of $S$. pombe cells improved the transformation efficiency to the point of practicality.

The $S$. pombe strains ATCC38399 $\left(h^{-}\right.$leu1-32), ATCC38436 $\left(h^{-}\right.$ura4294) (ATCC, Manassas, VA, USA), and TK107 ( $h^{-}$phh1::ura4 ${ }^{+}$ura4-D18 leu1-32) were used as the recipients for plasmids pAL7 and pAU5 $(8,9)$. The plasmids were isolated and purified using the Plasmid Mini Kit (Qiagen GmbH, Hilden, Germany).

The electroporation procedure was based on a cryopreservation method that has been previously described (10). $S$. pombe cells were grown in synthetic defined (SD) medium [0.67\% Bacto $^{\mathrm{TM}}$ yeast nitrogen base (Difco Laboratories, Detroit, MI, USA) without amino acid and $2 \%$ glucose] to a density of $1 \times 10^{7}$ cells $/ \mathrm{mL}$ at $30^{\circ} \mathrm{C}$. The culture medium was supplemented with 150 $\mu \mathrm{g} / \mathrm{mL}$ leucine or uracil, depending on the particular strains. The culture was placed on ice for $15 \mathrm{~min}$ just before harvesting. The cells were collected by centrifugation at $1600 \times g$ for $5 \mathrm{~min}$. The resulting pellet was washed three times with ice-cold sterilized water and then suspended in ice-cold 2.0 M sorbitol to give $5 \times 10^{8}$ cells $/ \mathrm{mL}$. Aliquots of $0.1 \mathrm{~mL}$ of the cell suspension were dispensed into 1.5-mL QSP ${ }^{\circledR}$ microcentrifuge tubes (Porex Bio Products, Petaluma, CA, USA), which were then slowly frozen for storage in a freezer at $-80^{\circ} \mathrm{C}$. For each electroporation, the frozen competent cells were quickly thawed in a water bath at $30^{\circ} \mathrm{C}$, followed by washing once with $1 \mathrm{~mL}$ of ice-cold $1.0 \mathrm{M}$ sorbitol by centrifugation at $1600 \times g$. The final pellet was resuspended in 1.0 $\mathrm{M}$ sorbitol to give $1 \times 10^{9}$ cells $/ \mathrm{mL}$. The cell suspension was mixed with $0.1 \mathrm{ng}$ of purified plasmid DNA and then transferred to a chilled cuvette with a $0.2-\mathrm{cm}$ electrode gap. A high electric pulse was applied to the cell suspension at $2.1 \mathrm{kV}, 25 \mu \mathrm{F}$, $200 \Omega$, using the Gene Pulser $^{\circledR}$ II with Pulse Controller Plus (Bio-Rad Laboratories, Hercules, CA, USA). The electroporated cells were immediately transferred in hyperosmotic sorbitol solution buffer and postincubated at $30^{\circ} \mathrm{C}$. A $0.2-\mathrm{mL}$ aliquot was spread on minimal selection plates $(0.67 \%$ yeast nitrogen base without amino acid, 2\% glucose, and 2\% agar). Transformant colonies appeared in 4-6 days at $30^{\circ} \mathrm{C}$.
The transformation efficiency of Saccharomyces cerevisiae cells can be markedly increased by spreading them on a selection plate containing $1.0 \mathrm{M}$ sorbitol as an osmotic stabilizer for a long-term period of 4-6 days until colonies form (11). Unfortunately, this sorbitol treatment reduces the efficiency of $S$. pombe cell transformation (3). Figure 1 shows the effects of each of the three sorbitol solution buffers on the transformation efficiency of $S$. pombe $\left(l e u^{-}\right)$during the postincubation period. The electroporated cells were postincubated in osmotic sorbitol solutions with $25 \mathrm{mM}$ HEPES, pH 7.0, and then spread on selection plates without sorbitol. The efficiency at $1.0 \mathrm{M}$ sorbitol increased by approximately 5-fold until $30 \mathrm{~min}$ of incubation but then gradually decreased. This result indicates that a long-term incubation on a selection plate with $1.0 \mathrm{M}$ sorbitol is not suitable for $S$. pombe. By increasing the osmotic concentration from 1.0 to $2.0 \mathrm{M}$ sorbitol, the efficiency further increased; the effective periods began sooner but did not last as long. Thus, the best efficiency was obtained at 2.0 M sorbitol for 5-15 min. Under these conditions, the efficiency was raised by approximately 1 order of magnitude. Efficiency decreased markedly after 30

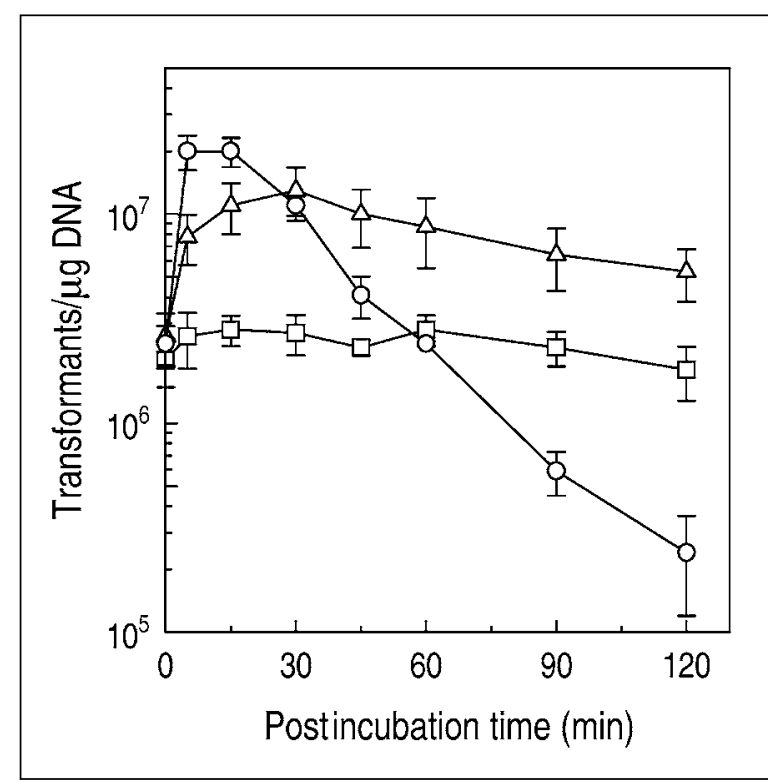

Figure 1. Effects of the postincubation period of the osmotic sorbitol solutions on transformation efficiency. Schizosaccharomyces pombe $\left(\mathrm{leu}^{-}\right)$cells were postincubated with $25 \mathrm{mM}$ HEPES, pH 7.0, in $0.5(\square), 1.0(\Delta)$, and $2.0 \mathrm{M}(\mathrm{O})$ sorbitol. Data represent the mean $(\overline{\times}$ $\pm \mathrm{SD})$ of five experiments. 
min or longer. Postincubation in $0.5 \mathrm{M}$ sorbitol close to isosmotic solution had no effect on the efficiency.

Although the absence of $\mathrm{pH}$ buffer slightly increased the efficiencies at 1.0 and $1.5 \mathrm{M}$ sorbitol compared to no postincubation treatment, the addition of HEPES, $\mathrm{pH} 7.0$, significantly increased efficiency between 1.0 and 2.0 M sorbitol (Figure 2). This result shows that it was necessary to add $\mathrm{pH}$ buffer to the hyperosmotic sorbitol solution. The optimal $\mathrm{pH}$ was 7.0 even though the $\mathrm{pH}$ buffers ranged from $\mathrm{pH} 5.0$ to 8.0.

Although electric pulse conditions certainly affect electroporation experiments, the transformation efficiency of postincubated $S$. pombe cells was constantly about one order of magnitude higher than in cells with no postincubation within $7.0-12.5 \mathrm{kV} / \mathrm{cm}$. The optimum conditions for an electric field strength of $10-11 \mathrm{kV} / \mathrm{cm}$ were almost the same whether or not the cells underwent post-pulse incubation.

In electroporation procedures for other yeast species, postincubation in culture medium is rarely carried out for cell recovery after the application of an electric pulse $(12,13)$. For $S$. pombe, however, the addition of SD medium to hyperosmotic sorbitol solution buffer

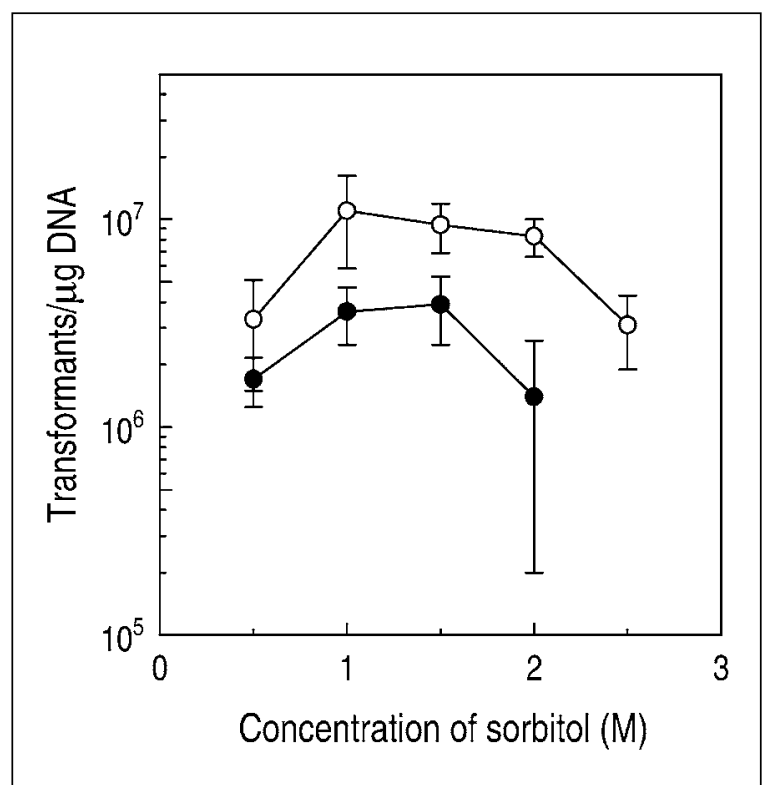

Figure 2. Effects of various concentrations of sorbitol on transformation efficiency. Schizosaccharomyces pombe (leu $\left.{ }^{-}\right)$cells were postincubated with $25 \mathrm{mM}$ HEPES, $\mathrm{pH} 7.0$ (o), and without $\mathrm{pH}$ buffer $(\bullet)$ for $60 \mathrm{~min}$. The efficiency of the nonincubated cells was $2.2 \pm 0.7$ $\times 10^{6} / \mu \mathrm{g}$ DNA. Data represent the mean $(\overline{\times} \pm \mathrm{SD})$ of five experiments. did not sufficiently affect hyperosmotic postincubation. On the other hand, when $S$. pombe cells were pulsed in $30 \%$ PEG 4000 and then continuously postincubated, permeability increased as membrane pores became enlarged (7). In contrast, the efficiency decreased only gradually when the cells pulsed in 1.0 M sorbitol were immediately transferred and postincubated in $30 \%$ PEG 4000 with pH buffer.

A similar profile of sorbitol concentrations and incubation periods was observed in another strain of $S$. pombe $\left(u r a^{-}\right)$. The efficiency of the cells postincubated in $2.0 \mathrm{M}$ sorbitol for 10 min increased approximately 15 -fold. Furthermore, to determine whether or not the hyperosmotic postincubation would be applicable to osmo-sensitive strains, S. pombe (strain TK107) was tested $(9,14)$. Efficiency at $2.0 \mathrm{M}$ sorbitol for $10 \mathrm{~min}$ increased approximately 4-fold, but there was no effect at $1.0 \mathrm{M}$ sorbitol for $30 \mathrm{~min}$ because of the longer exposure to high osmolarity.

We previously reported that pretreatment with DTT increased the transformation efficiency of $S$. pombe by electroporation (4). In the present study, a combination of DTT pretreatment with hyperosmotic postincubation further improved efficiency. A maximum transformation efficiency of $5.0 \pm$ $1.1 \times 10^{7} / \mu \mathrm{g}$ DNA was obtained when $S$. pombe $\left(l e u^{-}\right)$cells pretreated with DTT were postincubated in $2.0 \mathrm{M}$ sorbitol with $25 \mathrm{mM}$ HEPES, pH 7.0, at $30^{\circ} \mathrm{C}$ for $10 \mathrm{~min}$. This simple and rapid procedure using hyperosmotic post-pulse incubation will help to fulfill the demand for high-transformation efficiency in gene expression and functional analyses.

\section{ACKNOWLEDGMENTS}

We would like to thank Dr. Koei Okazaki, Dr. Koichi Tanaka, and Dr. Hiroto Okayama for providing yeast strains and plasmids.

\section{REFERENCES}

1.Hood, M.T. and C. Stachow. 1990. Transformation of Schizosaccharomyces pombe by electroporation. Nucleic Acids Res. 18:688

2.Prentice, H.L. 1992. High efficiency transformation of Schizosaccharomyces pombe by electroporation. Nucleic Acids Res. 20:621.

3.Ishiguro, J. and W. Kobayashi. 1995. A practical method for fission yeast transformation by electroporation. Jpn. J. Genet. 70:1-6.

4.Suga, M. and T. Hatakeyama. 2001. High efficiency transformation of Schizosaccharomyces pombe pretreated with thiol compounds by electroporation. Yeast 18:1015-1021.

5.Suga, M., I. Kusanagi, and T. Hatakeyama. 2003. High osmotic stress improves electrotransformation efficiency of fission yeast. FEMS Microbiol. Lett. 225:235-239.

6.Suga, M. and T. Hatakeyama. 2003. Highefficiency electroporation by freezing intact yeast cells with addition of calcium. Curr. Genet. 43:206-211.

7.Hood, M.T. and C. Stachow. 1992. Influence of polyethylene glycol on the size of Schizosaccharomyces pombe electropores. Appl. Environ. Microbiol. 58:1201-1206.

8.Okazaki, K., N. Okazaki, K. Kume, S. Jinno, K. Tanaka, and H. Okayama. 1990 High-frequency transformation method and library transducing vectors for cloning mammalian cDNAs by trans-complementation of Schizosaccharomyces pombe. Nucleic Acids Res. 18:6485-6489.

9.Kato, T., Jr., K. Okazaki, H. Murakami, S. Stettler, P.A. Fantes, and H. Okayama. 1996. Stress signal, mediated by a Hog1-like MAP kinase, controls sexual development in fission yeast. FEBS Lett. 378:207-212.

10.Suga, M., M. Isobe, and T. Hatakeyama. 2000. Cryopreservation of competent intact yeast cells for efficient electroporation. Yeast 16:889-896.

11.Becker, D.M. and L. Guarente. 1991. Highefficiency transformation of yeast by electroporation. Methods Enzymol. 194:182-187.

12.Meilhoc, E., J.M. Masson, and J. Teissié. 1990. High efficiency transformation of intact yeast cells by electric field pulses. Bio/ Technology 8:223-227.

13.Iborra, F. 1993. High efficiency transformation of Kluyveromyces marxianus by a replicative plasmid. Curr. Genet. 24:181-183.

14.Ohmiya, R., H. Yamada, K. Nakashima, H. Aiba, and T. Mizuno. 1995. Osmoregulation of fission yeast: cloning of two distinct genes encoding glycerol-3-phosphate dehydrogenase, one of which is responsible for osmotolerance for growth. Mol. Microbiol. 18:963-973.

Received 28 September 2003; accepted 12 November 2003.

Address correspondence to Minoru Suga, Department of Materials and Biosystem Engineering, Toyama University, 3190 Gofuku Toyama-City, Toyama 930-8555, Japan.e-mail:suga@eng.toyama-u.ac.jp 